Research Article

\title{
Development and Validation of Internet of Things (IoT) based Automated System for Controlling the Environmental Factors in Tunnel Farming
}

\author{
Muhammad Yamin ${ }^{1 *}$, Usama Ali Zafar', Ghulam Usman², Muhammad Nauman ${ }^{1}$, Muhammad Rizwan \\ Muhammad Nadeem ${ }^{1}$, Muhammad Azhar Ali ${ }^{1}$ and Usman Haider ${ }^{1}$
}

${ }^{1}$ Faculty of Agricultural Engineering and Technology, University of Agriculture Faisalabad, 38000, Pakistan; ${ }^{2}$ Water Management Training Institute, Lahore, 38000, Pakistan; ${ }^{3}$ Northwest Institute of Eco-Environment and Resources, University of Chinese Academy of Sciences, China.

\begin{abstract}
Tunnel farming is getting popular in the farmer's community of Pakistan due to the possibility of growing off-season vegetable crops with high yield in a controlled environment. In the current study, the development and validation of IoT system consisting of monitoring and control units were carried out for controlling the environmental factors in tunnel farming. Three tunnels were set for monitoring the environmental factors using temperature, humidity and soil moisture sensors. Two of three tunnels were fit with control units of exhaust fans and air heaters and a water pump for controlling the temperature and soil moisture. During the testing and validation of the system, temperatures recorded through DHT-21 sensor and thermometer in tunnel 1,2 and 3 had strong correlations of $0.9986,0.998$ and 0.9978 respectively. Similarly, strong correlations of 0.9987, 0.9994 and 0.998 were found for RH (\%) measured through DHT21 sensor and RH meter for tunnel 1,2 and 3 respectively. For soil moisture measurement, similar correlations were observed for resistive soil moisture sensor and oven dry method. It was explored that an increase in temperature through an air heater decreases the RH in tunnel 1 and 2 compared to tunnel 3 which has higher RH because it was not installed with air heater and exhaust fan. System controlled the temperature and soil moisture within adjusted limits of $22-27^{\circ} \mathrm{C}, 17-23 \%$ for tunnel 1 and $19-22{ }^{\circ} \mathrm{C}$, and $19-23 \%$ for tunnel 2.

Received | February 23, 2021; Accepted | April 10, 2021; Published | June 30, 2021

*Correspondence | Muhammad Yamin, Faculty of Agricultural Engineering and Technology, University of Agriculture Faisalabad, 38000, Pakistan; Email: yamin529@uaf.edu.pk

Citation | Yamin, M., U.A. Zafar, G. Usman, M. Nauman, M. Rizwan, M. Nadeem, M.A. Ali and U. Haider. 2021. Development and validation of internet of things (IoT) based automated system for controlling the environmental factors in tunnel farming. Sarbad Journal of Agriculture, 37(3): 839-846.
\end{abstract}

DOI | https://dx.doi.org/10.17582/journal.sja/2021/37.3.839.846

Keywords | Tunnel farming, Internet of things (IoT), Environmental factors, Temperature, RH, Soil moisture

\section{Introduction}

A griculture, vital for the economy, not only benefits the country itself but also uplift the regional imports and exports. Agriculture contributes about $21 \%$ of the Pakistan's Gross Domestic Product
(GDP). As the country is facing problems in this sector, so it's important to enhance the research and development and adopt new practices for the increase of production. Due to increase in technology and modern practices, industrialization is taking place in agriculture (Hut, 2014). 
Population is increasing with time which is creating great problems regarding food security. Luckily, technology is evolving to fulfill the food and fiber needs of the people (Sheikh et al., 2012). Keeping that in view, the Government of Punjab, Pakistan launched a project named "Fruits and Vegetable Development Project" in 2005 by introducing technology particularly tunnel farming at a major level. It helped the farmers to grow more vegetables and fruits. As the tunnel farming started to take its root in different cities of Punjab like Vehari, Melsi, Arifwala and also it spread very fast in the districts of Faisalabad,Jhang, Multan and Rahim Yar Khan, as the government marked these cities on the top of tunnel marking hubs in Punjab. In 1948 tunnel technology was adopted for the first time in Pakistan (Fatima et al., 2017). Now in Pakistan large community of farmers have adopted this practice and have positively earned economic and production benefits. More than 300,000 acres are being utilized for tunnel farming practice (Aazim, 2016).

As the tunnel farming is growing with time, to make it more effective, efforts are required from researchers. National Agricultural Research Center (NARC), Islamabad and Ayyub Agricultural Research Institute (AARI), Faisalabad took initiative to bring the new technologies with tunnel farming. As the technology is growing, the farmers are more eager to apply it on different crops. As technology advanced, needs of people are also increased with same proportion and new directions are needed to grow crops which will help to fulfill the needs of the modern era. Technology and research came on same page and worked together to discover different type of growing techniques (Aazim, 2016).

Temperature is a key factor influencing plant growth rates. Water deficits and surplus soil water intensify the temperature effects, indicating that it will be important to consider the relationship of temperature and water. A given range of maximum and minimum temperatures for each species forms the limits of measurable growth (Shamshiri et al.,2016). Acceptable temperature for vegetative growth is usually higher for most plant species than for reproductive development (Hatfield et al., 2011; Lobell and Burke, 2008).

In greenhouses, humidity is the most important and hard factor to regulate from all environmental factors. The humidity level in greenhouses cannot be managed perfectly by even the most advanced environmental control equipment (Karkhile and Ghuge, 2015; Körner and Challa, 2003).

Internet of Things (IoT) reveals its expertise in every discipline of the human life especially in agriculture and particularly in tunnel farming. By creating a gadget of interrelated sensors and computing devices, it allows the transfer of information without human interaction. It is executed by collecting records of temperature, rainfall, humidity, soil content material etc. and is able to take decisions to reduce water and efforts for higher exceptional. IoT bears the ability to cover all the components of smart tunnel farming starting from monitoring, productivity, integrity, safety, and mobility of records alongside transportation of completed product (Jayaraman et al., 2016).

This study covers the environmental control by IoT for the cucumber (Cucumis sativus) through automated tunnel. The concept of IoT is the future for the agriculture sector and had started serving the means. Essentials of crop like nutrition, fertilizer and water requirement are all electronically monitored and controlled (Jayaraman et al., 2016; Khummanee et al., 2018). As assessed by the Food and Agriculture Organization U.N., up to 2050 food production must be increased by $60 \%$ to provide for expected population increase of 9 billion (GOP, 2015).

IoT essentially facilitate within the production of microclimate which is key element of plant growth and is far pretty dependent upon the temperature and other condition in the greenhouse. The features of microclimate are extracted using wireless sensors which are basically series of devices possessing sensing talents and are connected using a shape of a signal i.e. Radio network. It consists of a simple agricultural record gadget, where in relay of sensor nodes unfold out in order to direct the statistics to network capable application processor. Intelligent devices are distributed over the Internet over an architectural model. These phenomena underline the fact that the Internet of Things is not accessible because of its two-fold physical and digital nature. It must be viewed as a technical background, but also as a human-led experience (Kortuem et al., 2009). Therefore, intelligent farm practices like improved decision making programs, better sensing technologies and better communication solutions must be considered in agricultural farming (Alam et al., 2018; Munir et al., 2018). This technology 
helps to identify the specific variety of crop which can give maximum production. Suitable conditions for the specific variety of crop can also be adjusted to get good yield. If this way of farming is adopted by farmer, it can revolutionize the agriculture sector (Jayaraman et al., 2016; Zhang et al., 2015).

In current study, the development and validation of Io $T$ based automated system consisting of monitoring and control units was carried out for controlling the environmental factors like temperature, humidity and soil moisture in tunnel farming.

\section{Materials and Methods}

Three demonstration cucumber tunnels, as shown in Figure 1, were constructed in the field for monitoring the environmental factors like temperature, relative humidity (RH) and soil moisture using ESP32 microcontroller, humidity and temperature sensor (DHT-21) and soil moisture sensor. Tunnel 1 and 2 were also equipped with the environment controlling equipment like two exhaust fans (220 VAC), two air heaters (220 VAC, $2 \mathrm{~kW}$ ) and a $12 \mathrm{VDC}$ water pump (Table 1 and Figure 2). The monitoring and/ or controlling devices of each tunnel were integrated with one ESP32 microcontroller separately.

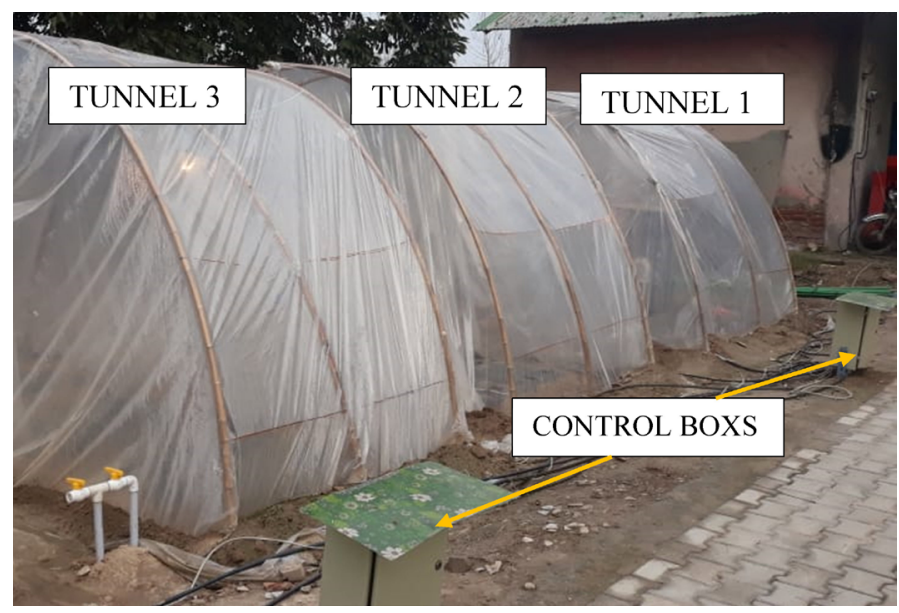

Figure 1: Tunnels installed with Io T controllers.

Figure $3 \mathrm{~A}$ shows the programming algorithm for monitoring and controlling the temperature for tunnel 1 and 2. For tunnel 1, upper and lower limits of temperature were set as $27^{\circ} \mathrm{C}$ and $22^{\circ} \mathrm{C}$. As temperature rises above $27^{\circ} \mathrm{C}$ exhaust fan turns on and below $22^{\circ} \mathrm{C}$, the electric air heater starts working. Similarly, for tunnel 2, the upper and lower limits of temperature were set as $22^{\circ} \mathrm{C}$ and $19^{\circ} \mathrm{C}$ with similar operation of exhaust fan and air heater. Further, ESP32 microcontroller checks the moisture contents of tunnel 1 and 2 and controls in the range of $18-22 \%$. At the same time ESP32 microcontroller sends temperature, $\mathrm{RH}$ and soil moisture data to an online database named Firebase which is the extension of Google Inc. This platform having cloud function helped to create a customized web database application which was synchronized with the ESP32 microcontroller, allowing the module to transfer the collected data to Firebase after every $15 \mathrm{~min}$ (Google, 2020). The data are accessible anywhere in the world through internet facility and are displayed on this portal in tabular form (Figure 4).

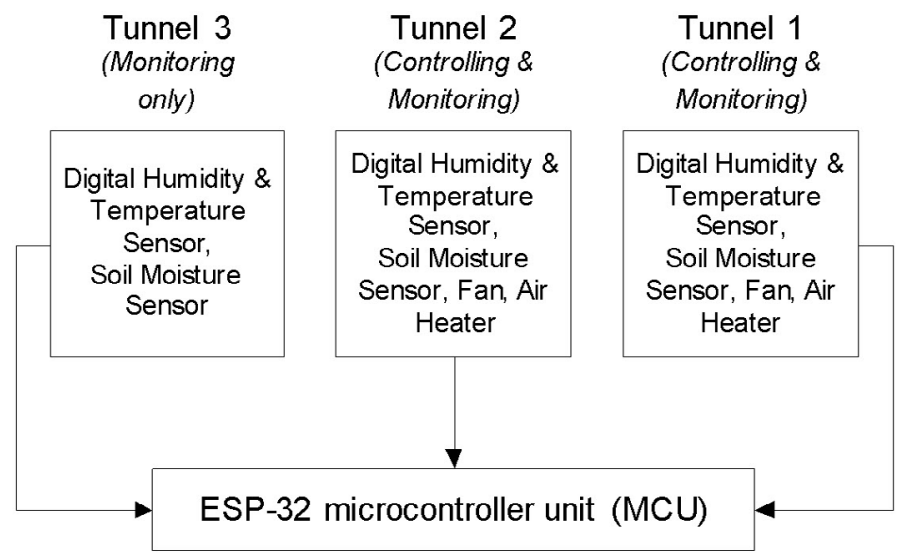

Figure 2: Operational diagram for tunnels.
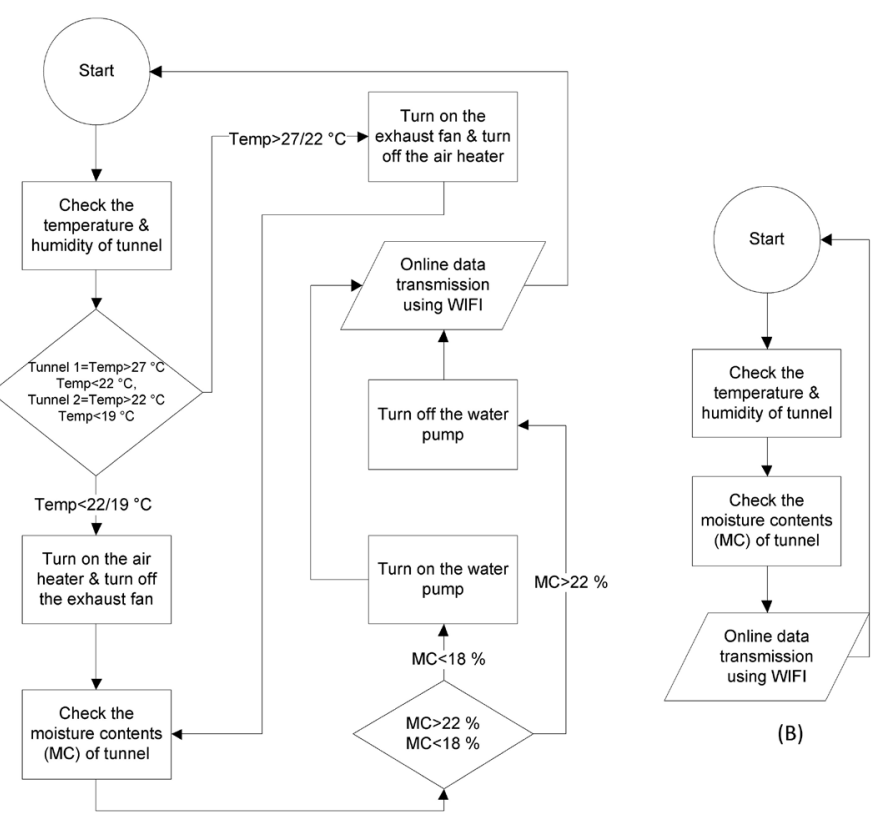

(B)

(A)

Figure 3: Algorithm for temperature monitoring and control for $(A)$ tunnel 1 and 2, (B) tunnel 3.

Tunnel 3 was constructed for only monitoring the mentioned environmental factors; therefore, ESP32 microcontroller checks temperature, $\mathrm{RH}$ and soil moisture and transmits to Firebase as shown in programing algorithm of Figure 3B. 
Table 1: Equipment specifications.

$\begin{array}{ll}\text { S. No } & \text { Component/Equipment } \\ 1 & \text { ESP32 controller } \\ 2 & \text { Humidity and temperature sensor (DHT-21) } \\ 3 & \text { Soil moisture sensor } \\ 4 & \text { Exhaust fan } \\ 5 & \text { Air heater } \\ 6 & \text { Water pump }\end{array}$

Specifications

3-3.6 VDC, Wifi (802.11 b/g/n), $40 \mathrm{MHz}$ Crystal, SP flash $4 \mathrm{MB}$

5 VDC, Single digital data line

Capacitive, 0-5 VDC (Analog)

$220 \mathrm{VAC}, 1.5 \mathrm{~A}, 1350 \mathrm{RPM}, 11 \mathrm{~m} / \mathrm{min}$

Model: Smile-2000BT, 220 VAC, 9 A, 2 kW

Model: FL-3203, 12 VDC, 5 A, 5 L/min

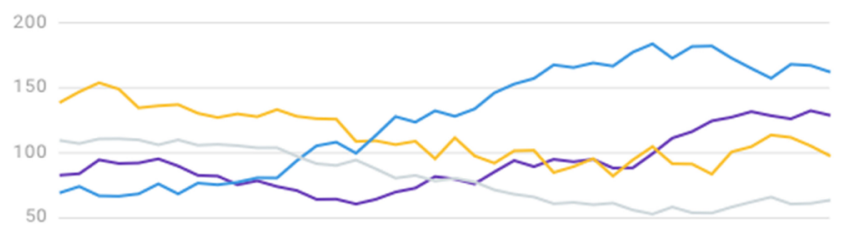

Storage Analytics

Figure 4: Interface of Firebase data portal.

During the testing of developed IoT based control system, the data of same environmental factors were recorded manually for comparison purposes through correlation analysis done in Statisix v8. Mercury thermometer was used to obtain temperature and digital RH (Model: HTC-1) was used for the measurement of $\mathrm{RH}$ in the range of $10-99 \%$.

\section{Results and Discussion}

\section{Temperature comparison of Tunnel 1, 2 and 3}

Comparison for data collected by sensor and manual temperature is shown in Figure 6. In tunnel 1, temperature from DHT-21 sensor varies between 21 and $25^{\circ} \mathrm{C}$ while temperature from thermometer varies between 19 and $24^{\circ} \mathrm{C}$ (Figure 5). Variation of temperature in tunnel 1 develops a decent correlation between temperatures measured through DHT-21 sensor and thermometer. The correlations of 0.9986 and $\mathrm{P} \leq 0.05$ in Table 2 indicate a strong association between temperatures measured through DHT-21 sensor and thermometer in tunnel 1 . The data shows a good control of temperature around the prescribed limits of $22-27^{\circ} \mathrm{C}$.

Tunnel 2 illustrates similar trend of temperatures measured through DHT-21 sensor and thermometer which ranges $18-23{ }^{\circ} \mathrm{C}$ and $19-22{ }^{\circ} \mathrm{C}$ respectively (Figure 6) following a strong correlation of 0.998 as shown in Table 2. Tunnel 1 and 2 were automated having temperature sensing system and control through exhaust fans and air heaters. Although tunnel 3 has no environmental control and monitoring only but the trend of temperatures measured through DHT-21 sensor and thermometer is same with a strong correlation of 0.9978 and temperature rages of $14-22{ }^{\circ} \mathrm{C}$ and $14-23^{\circ} \mathrm{C}$ respectively (Figure 7). Figure 8 demonstrates the temperature comparison for all three tunnels showing that overall tunnel 1 and 2 have higher temperatures compared to the tunnel 3. It shows that developed system increased the temperatures of tunnel 1 and 2 by turning on the heater in prescribed temperature ranges of $22-27^{\circ} \mathrm{C}$ and 19 $22^{\circ} \mathrm{C}$, respectively. Ortiz-Bobea (2013) established a predictive crop yield model which represents similar non-linear temperature effects and non-linear soil moisture effects during the crop season.

Table 2: Correlation comparison of temperature for all tunnels.

$\begin{array}{ll}\text { Correlation comparison of temperature for tunnel } 1 \\ \text { Temperature recorded } \\ \text { on thermometer }\end{array}$
$\begin{array}{lll}\text { DHT-21 } & \text { Pearson correlation } & 0.9986 \\ \text { sensor } & \text { P-Value } & 0.00^{*} \\ \text { Correlation } & \text { comparison of temperature for tunnel } 2 \\ \text { DHT-21 } & \text { Pearson correlation } & 0.998 \\ \text { sensor } & \text { P-Value } & 0.00^{*} \\ \text { Correlation } & \text { comparison of temperature for tunnel } 3 \\ \text { DHT-21 } & \text { Pearson correlation } & 0.9978 \\ \text { sensor } & \text { P-Value } & 0.00^{*} \\ \text { * = Significant } & (P \leq 0.05) .\end{array}$

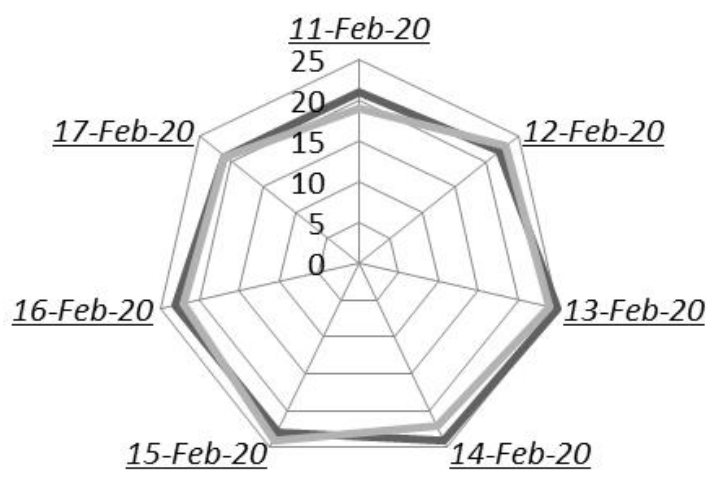

$\longrightarrow$ DHT-21 sensor $\left({ }^{\circ} \mathrm{C}\right) \longrightarrow$ Thermometer $\left({ }^{\circ} \mathrm{C}\right)$

Figure 5: Temperature comparison for tunnel 1. 


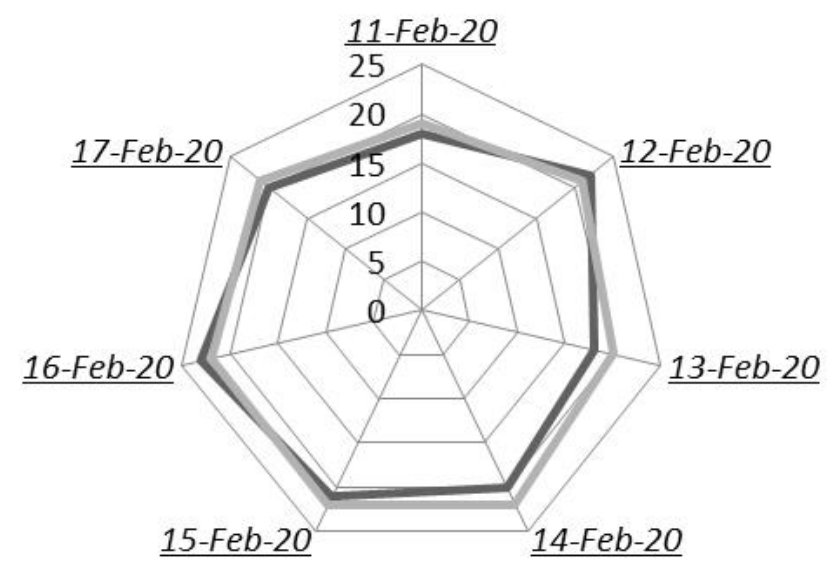

DHT-21 sensor $\left({ }^{\circ} \mathrm{C}\right) \longrightarrow$ Thermometer $\left({ }^{\circ} \mathrm{C}\right)$

Figure 6: Temperature comparison for tunnel 2.

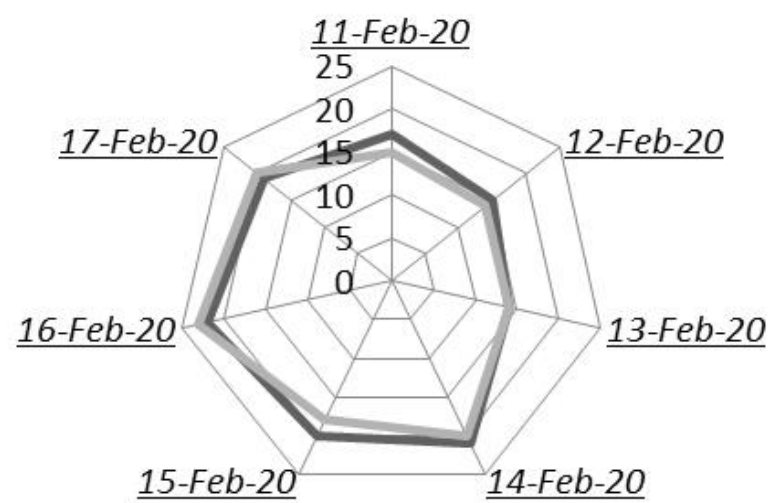

$\longrightarrow$ DHT-21 sensor $\left({ }^{\circ} \mathrm{C}\right) \longrightarrow$ Thermometer $\left({ }^{\circ} \mathrm{C}\right)$

Figure 7: Temperature comparison for tunnel 3 .

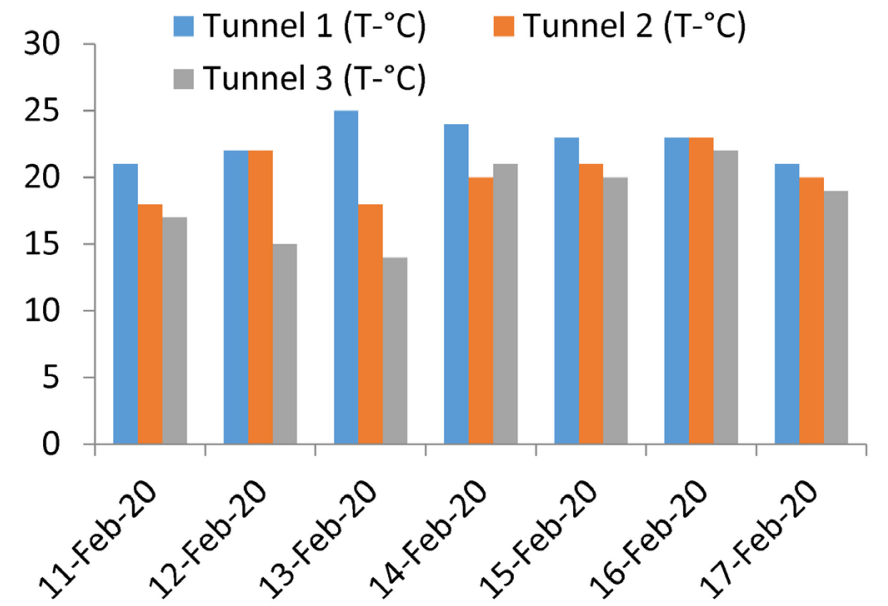

Figure 8: Temperature comparison for all tunnels.

Relative humidity comparison of Tunnel 1, 2 and 3 In tunnel 1, RH from DHT-21 sensor varies between 60 and $66 \%$ while $\mathrm{RH}$ from $\mathrm{RH}$ meter varies between 60 and $65 \%$ (Figure 9). A strong correlation of RH from both instruments was observed at 0.9987 with $\mathrm{P} \leq 0.05$ (Table 3).
Table 3: Correlation comparison of $R H$ (\%) for all tunnels.

\section{Correlation comparison of RH (\%) for tunnel 1}

$\begin{array}{lll} & & \text { RH meter } \\ \text { DHT-21 sensor } & \text { Pearson correlation } & 0.9987 \\ & \text { P-Value } & 0.00^{*}\end{array}$

Correlation comparison of RH (\%) for tunnel 2

DHT-21 sensor Pearson correlation 0.9994 P-Value $0.00^{*}$

Correlation comparison of RH (\%) for tunnel 3 P-Value $0.00^{*}$

* = Significant $(P \leq 0.05)$.

A similar trend was observed in tunnel 2 with correlation coefficient of 0.9994 at $\mathrm{P} \leq 0.05$ with $\mathrm{RH}$ ranges of $65-72 \%$ and $60-71 \%$ using DHT-21 sensor and RH meter respectively (Table 3 and Figure 10). In tunnel 3, the trend of $\mathrm{RH}$ measured through DHT21 sensor and $\mathrm{RH}$ meter is similar with comparatively higher $\mathrm{RH}$ range of 71-84 \% and 70-83\% with a strong correlation of 0.998 (Figure 11 and Table 3). Figures 8 and 12 cumulatively explore that an increase in temperature through air heater decreases the $\mathrm{RH}$ in tunnel 1. Same trend was observed in tunnel 2 while tunnel 3 has higher RH because it was not installed with air heater and exhaust fan.

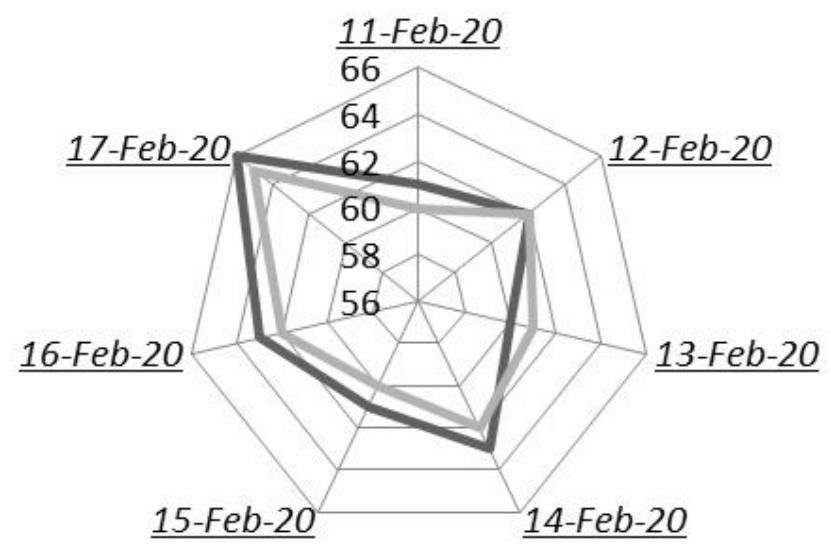

- DHT-21 sensor (\%) — $\quad$ RH meter (\%)

Figure 9: $R H$ comparison for tunnel 1.

Comparison of soil moisture for tunnel 1, 2 and 3

On the part of soil moisture, resistive soil moisture sensor has given the reading of $18-23 \%$ on volumetric basis compared to the 19-23\% through oven dry method (Figure 13). Ultimately, it developed a good correlation of 0.9920 at $\mathrm{P} \leq 0.05$ (Table 4). 


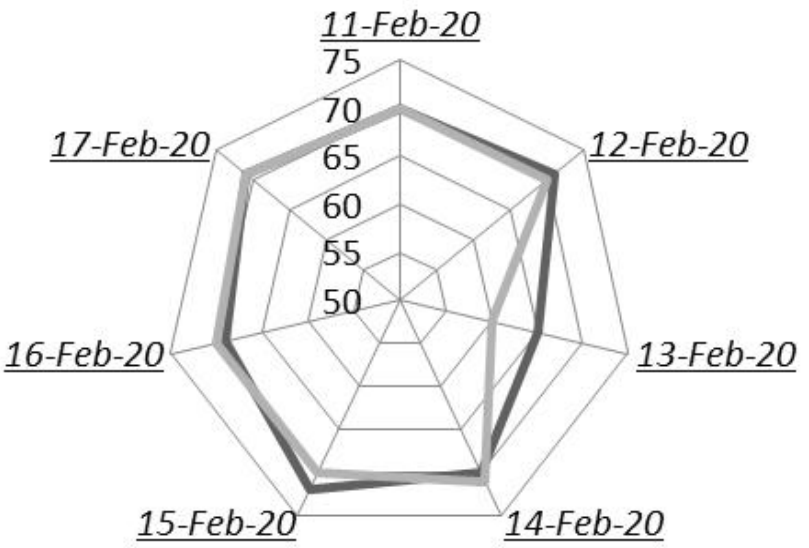

DHT-21 sensor (\%) RH meter (\%)

Figure 10: $R H$ comparison for tunnel 2.

Table 4: Correlation comparison of soil moisture for all tunnels.

Correlation comparison of soil moisture for tunnel 1 Oven dry method

Moisture sensor

$\begin{array}{ll}\text { Pearson correlation } & 0.9920 \\ \text { P-Value } & 0.0001^{*}\end{array}$

Correlation comparison of soil moisture for tunnel 2

Moisture sensor

$$
\begin{array}{ll}
\text { Pearson correlation } & 0.9951 \\
\text { P-Value } & 0.00^{*}
\end{array}
$$

Correlation comparison of soil moisture for tunnel 3

$\begin{array}{lll}\text { Moisture sensor } & \text { Pearson correlation } & 0.9976 \\ & \text { P-Value } & 0.00^{*}\end{array}$

* = Significant $(P \leq 0.05)$.

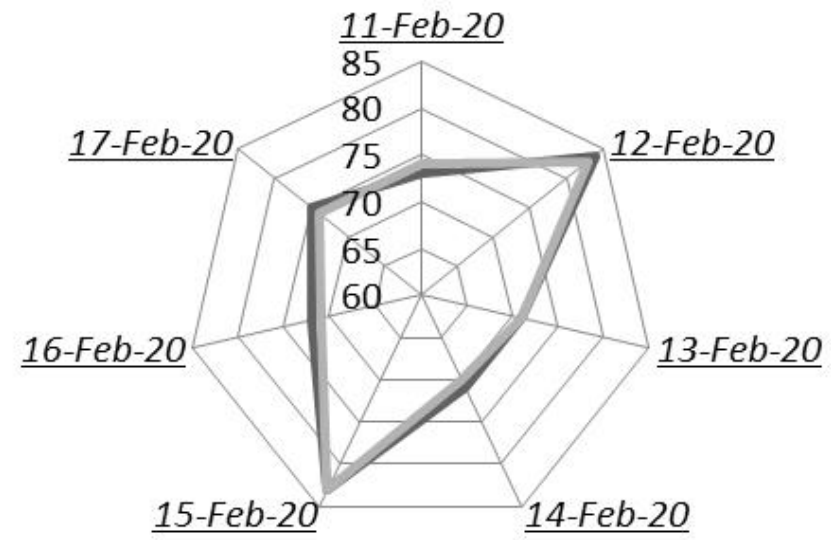

$\longrightarrow$ DHT-21 sensor (\%) $\quad$ RH meter (\%)

Figure 11: $R H$ comparison for tunnel 3.

A similar trend was seen in Tunnel 2 using soil moisture sensor and oven dry method which ranged from $17-23 \%$ and $19-23 \%$ respectively (Figure 14) following a strong correlation of 0.9951 as shown in Table 4. In tunnel 3, the trend of soil moisture

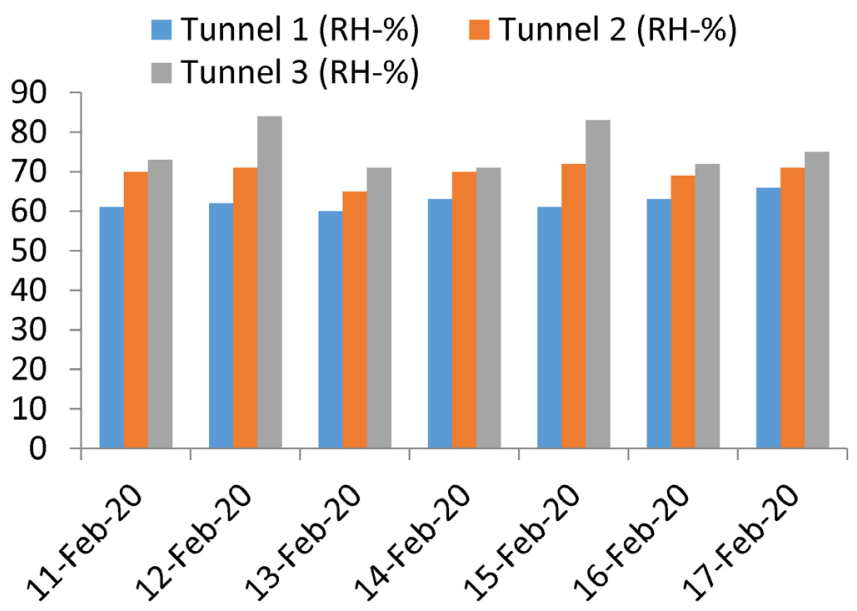

Figure 12: $R H$ comparison for all tunnels.
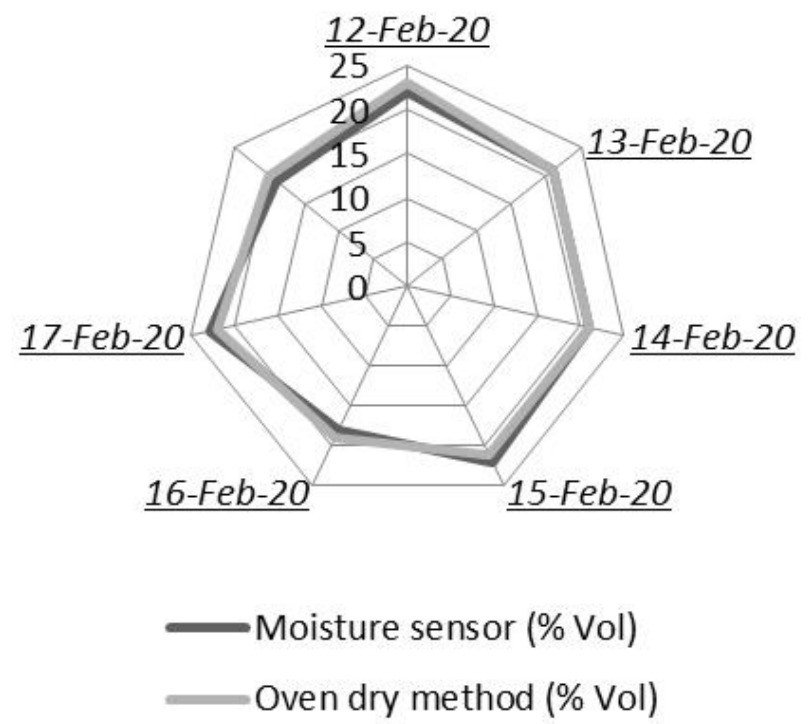

Figure 13: Soil moisture comparison for tunnel 1.

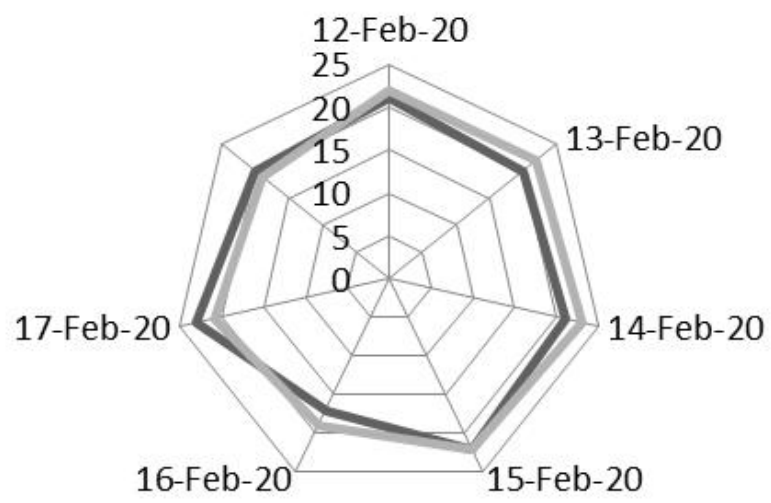

$$
\begin{aligned}
& \text { Moisture sensor (\% Vol) } \\
& \text { Oven dry method }(\% \mathrm{Vol})
\end{aligned}
$$

Figure 14: Soil moisture comparison for tunnel 2.

measured through soil moisture sensor and oven dry method is dissimilar to the tunnel 1 and 2 with higher soil moisture range of 22-30\% and 24-30\% using with a strong correlation of 0.9976 (Figure 15 
and Table 4). Since tunnel 3 was irrigated manually therefore, control of soil moisture in tunnel 3 could not be maintained leading to higher soil moisture and ultimately higher RH (Figures 12 and 16). This finding was in line with the study of Karim and Karim (2017) who worked on microclimate of crops. The predictive crop yield model of Ortiz-Bobea (2013) was based on similar non-linear soil moisture effects having non-linear temperature effects also.

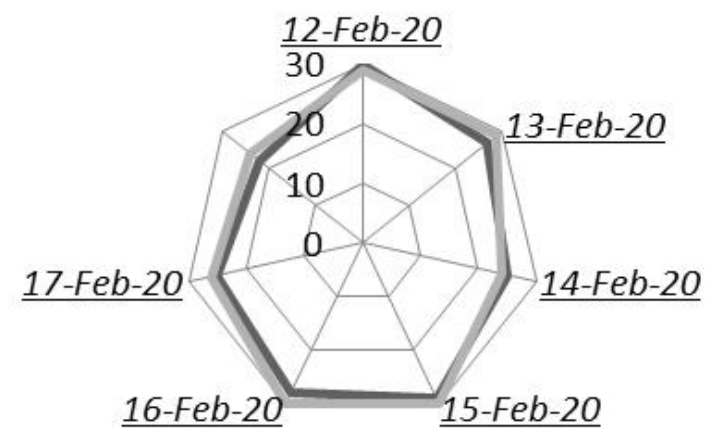

Moisture sensor (\% Vol)

Oven dry method (\% Vol)

Figure 15: Soil moisture comparison for tunnel 3.

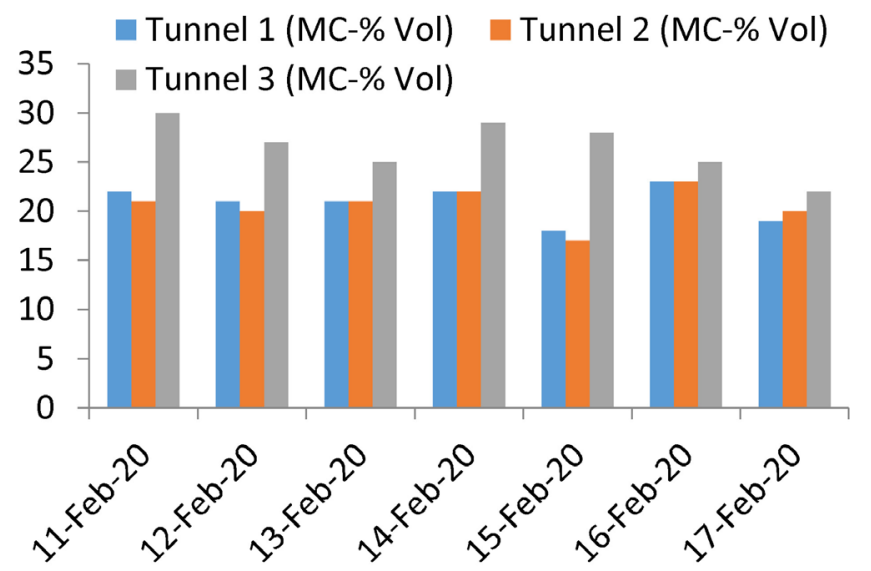

Figure 16: Soil moisture comparison for all tunnels.

\section{Conclusions and Recommendations}

The developed system effectively increased the temperatures of tunnel 1 and 2 using air heater in prescribed temperature ranges of $22-27^{\circ} \mathrm{C}$ and $19-$ $22^{\circ} \mathrm{C}$, respectively. Further, it was explored that an increase in temperature through air heater decreases the $\mathrm{RH}$ in tunnel 1 and 2 compared to the tunnel 3 which has higher $\mathrm{RH}$ because it was not installed with air heater and exhaust fan.

Since tunnel 3 was irrigated manually therefore, the control of soil moisture in tunnel 3 could not be maintained leading to higher soil moisture which increased the RH. System successfully transmitted the data on Firebase portal without any lag but it is important to inspect the system once in a month.

\section{Novelty Statement}

This manuscript describes the design of electronic controller for controlling the environment in tunnels farming. This will help to increase the production by managing the required temperature, humidity and soil moisture.

\section{Author's Contribution}

Muhammad Yamin and Usama Ali Zafar: Mainly planned the study.

Ghulam Usman: Collected the data.

Muhammad Yamin, Muhammad Nadeem and Muhammad Nauman: Analyzed the data.

Muhammad Yamin and Muhammad Rizwan: Wrote the manuscript.

Muhammad Azhar Ali and Usman Haider: Helped in writing the manuscript.

\section{Conflict of interest}

The authors have declared no conflict of interest.

\section{References}

Aazim, M., 2016. Tunnel farming gains ground. Islamabad: Dawn. https:/www.dawn.com/ news/1297525/tunnel-farming-gains-ground.

Alam, S., A. Hasssan, A. Bashir and M. Iqbal. 2018. Smart tunnel farming model: An inculcation of cloud computing with cortex for reliable agricultural production. Int. J. Sensor Netw. Data Commun., 7: 1-11. https://doi. org/10.4172/2090-4886.1000161

Fatima, H., L.K. Almas and B. Yasmin. 2017. Production efficiency analysis of capsicum (Bell Pepper) cropping system under the tunnels in Punjab, Pakistan. Annual Meeting, Alabama.

Google, 2020. Firebase. Google Inc. https:// firebase.google.com.

GOP, 2015. Fruit, vegetables and condiments statistics of Pakistan 2014-2015. Islamabad Ministry of National Food Security and research Economic Wing. Government of Pakistan.

Hatfield, J.L., K.J. Boote, B. Kimball, L. Ziska, 
R.C. Izaurralde, D. Ort, A.M. Thomson and D. Wolfe. 2011. Climate impacts on agriculture: Implications for crop production. Agron. J., 103: 351-370. https://doi.org/10.2134/ agronj2010.0303

Hut, B., 2014. Agriculture in Pakistan. An overview. Book Hut. http://www.bookhut.net/problemsof-agriculture-in-pakistan/.

Jayaraman, P.P., A. Yavari, D. Georgakopoulos, A. Morshed and A. Zaslavsky. 2016. Internet of things platform for smart farming: Experiences and lessons learnt. Sensors, 16: 1884. https:// doi.org/10.3390/s16111884

Karim, F. and F. Karim. 2017. Monitoring system using web of things in precision agriculture. Proc. Comput. Sci., 110: 402-409. https://doi. org/10.1016/j.procs.2017.06.083

Karkhile, S.G. and S.G. Ghuge. 2015. A modern farming techniques using android application. Int. J. Innov. Res. Sci. Eng. Technol., pp. 4.

Khummanee, S., S. Wiangsamut, P. Sorntepa and C. Jaiboon. 2018. Automated smart farming for orchids with the internet of things and fuzzy logic. Int. Conf. Inf. Technol. (InCIT). pp. 1-6. https://doi.org/10.23919/ INCIT.2018.8584881

Körner, O. and H. Challa. 2003. Process-based humidity control regime for greenhouse crops. Comput. Electron. Agric., 39: 173-192. https:// doi.org/10.1016/S0168-1699(03)00079-6

Kortuem, G., F. Kawsar, V. Sundramoorthy and D. Fitton. 2009. Smart objects as building blocks for the internet of things. IEEE Internet Comput., 14: 44-51. https://doi.org/10.1109/ MIC.2009.143
Lobell, D.B. and M.B. Burke. 2008. Why are agricultural impacts of climate change so uncertain? The importance of temperature relative to precipitation. Environ. Res. Lett., 3: 034007. https://doi.org/10.1088/17489326/3/3/034007

Munir, M.S., I.S. Bajwa, M.A. Naeem and B. Ramzan. 2018. Design and implementation of an IoT system for smart energy consumption and smart irrigation in tunnel farming. Energies, 11: 3427. https://doi.org/10.3390/en11123427

Ortiz-Bobea, A., 2013. Understanding temperature and moisture interactions in the economics of climate change impacts and adaptation on agriculture. Annu. Meet. Agric. Appl. Econ. Assoc., USA.

Shamshiri, R., D. Ahmad, W.I.W. Ismail, H.C. Man, A. Zakaria, M. Yamin and P. Van Beveren. 2016. Comparative evaluation of naturally ventilated screenhouse and evaporative cooled greenhouse based on optimal vapor pressure deficit. ASABE Annual International Meeting, USA.

Sheikh, S.M., M. Ahmed, S. Shahan and M.Z. Khan. 2012. Importance of Agricultural Sector in Pakistan. Interdisciplin. J. Contemp. Res. Bus., 3: 421.

Statistix, 2006. Statistix 8 user guide, version 1.0. Analytical Software, PO Box 12185, Tallahassee FL 32317 USA. Copyright (C) 2006 by Analytical Software.

Zhang, L., C. Li, Y. Jia and Z. Xiao. 2015. Design of greenhouse environment remote monitoring system based on android platform. Chem. Eng. Trans., 46: 739-744. 